\section{Alcohol use and misuse}

A lcohol use and misuse in Canada continues to be substantial. According to the latest data from the 2005 Canadian Addiction Survey, ${ }^{1} 79.3 \%$ of Canadians 15 years and older consume alcohol. Although not directly comparable to the Canadian Addiction Survey because of methodological differences, Canada's Alcohol and Other Drugs Survey in 1994 found that $74.7 \%$ of respondents reported that they consume alcohol. These findings suggest that rates of alcohol use in Canada remain high. The Canadian Addiction Survey data also suggest that $44.0 \%$ of Canadians who use alcohol drink at least once weekly and that $9.9 \%$ drink 4 or more times per week. Accordingly to guidelines for low-risk drinking, ${ }^{2}$ alcohol intake should not exceed I4 standard drinks per week for males, and 9 standard drinks per week for females. However, in $2005,17 \%$ of current drinkers in Canada engaged in hazardous drinking behaviours, $25.1 \%$ of whom were men and 8.9\% women. Among former and current drinkers, $24.2 \%$ reported that their drinking had caused harm to themselves or others. ${ }^{1}$

Alcohol-related mortality is also substantial in Canada. In 2002, I63I people aged 69 or less died of chronic diseases attributed to alcohol consumption; this figure translates to $2.4 \%$ of all deaths in this age group, nearly 43000 years of life lost prematurely and nearly $\mathrm{I} 25000$ hospital admissions because of alcoholrelated chronic diseases. ${ }^{3}$ Moreover, per capita alcohol consumption is positively correlated with total suicide-related mortality.

Lower age, male sex and a family history of alcoholism are risk factors for alcohol misuse. Psychiatric illness and illicit drug abuse are also highly prevalent among people who misuse alcohol. As well, cigarette smoking rates are reported to be as high as $80 \%-$ 90\% among people with alcoholism, and smoking-related disease is the primary cause of death among people recovering from alcoholism. ${ }^{4}$

Identifying problem drinkers is an important role for general practition-

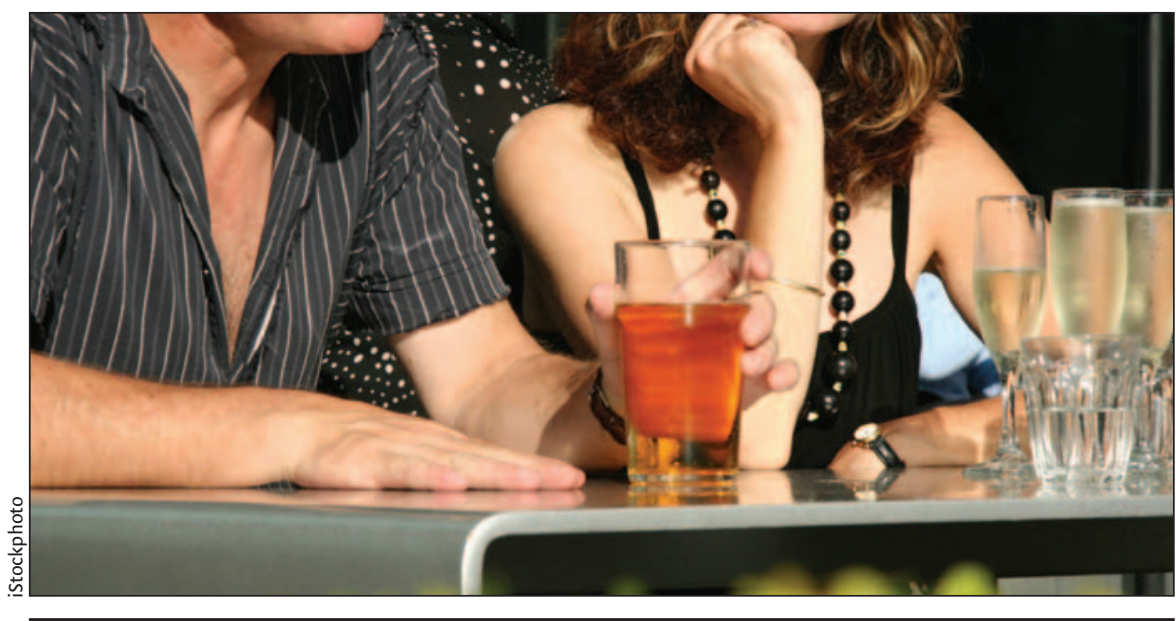

According to a 2005 survey, $17 \%$ of current drinkers in Canada engaged in hazardous drinking behaviours. Physicians can play a critical role in identifying problem drinkers, motivating them to address their heavy drinking and, if necessary, referring them for more specialized interventions.

ers. Simple screening tools such as the CAGE questionnaire - Have you felt you needed to cut down on your drinking? Have you felt annoyed by criticism of your drinking? Have you felt guilty about drinking? Have you felt you needed a drink first thing in the morning (eyeopener)? - have proven useful in clinical practice. Two affirmative answers with this questionnaire predict with $90 \%$ sensitivity an alcohol use disorder.

Participation in self-help groups (e.g., Alcoholics Anonymous) is particularly useful for problem drinkers. The psychosocial support provided is most helpful for the achievement of longterm sobriety, and membership in Alcoholics Anonymous has been linked to a reduced risk of alcohol-related suicide. Brief (e.g., less than 5 minutes) motivational interventions are considerably effective in encouraging problem drinkers to address their heavy drinking, and these interventions have been used successfully in primary care, emergency department and specialty care settings. For patients who do not respond to such brief interventions, more intensive behavioural interventions (typically offered in alcohol treatment programs), such as helping them develop coping skills and providing cognitive behavioural therapies, may help these patients to initiate alcohol abstinence or prevent relapse.

Several effective pharmacotherapies to help problem drinkers ${ }^{5}$ have been ap- proved by Health Canada. They include the alcohol-abuse detterent disulfiram (Antabuse) and the opioid receptor antagonist naltrexone (ReVia). Naltrexone appears to have some efficacy in reducing alcohol consumption and preventing relapse, but compliance is poor because of gastrointestinal side effects. A depot formulation of naltrexone (Vivitrol) is now available in the United States. The deterrent acamprosate (Campral) has been approved in Europe and the United States for treating alcohol dependence and preventing relapse. European studies have demonstrated the combined efficacy of naltrexone and acamprosate in preventing relapse; however, the COMBINE study in the United States did not show evidence of acamprosate's efficacy, alone or in combination with naltrexone, in preventing relapse. ${ }^{6}$ Off-label use of certain medications, such as the anticonvulsant topiramate and the serotonin $5-\mathrm{HT}_{3}$ receptor antagonist and antiemetic ondansetron, have shown considerable promise for the treatment of alcoholism.

Recent population-based and molecular genetic studies as well as neuroimaging investigations have shed much light on the pathophysiology of alcohol dependence and its relation to coexisting drug abuse and mental health disorders.

Although there are effective pharmacologic and behavioural treatments for alcohol use disorders, few people 
with such disorders receive treatment or participate in self-help groups, as indicated in a recent US study ${ }^{7}$ and the Canadian Addiction Survey. ${ }^{1}$ Therefore, the opportunity is critical for physicians to engage problem drinkers, especially since such contact is known to markedly increase treatment-seeking by these patients. Although effective alcohol control policies are important population-based strategies for addressing problem drinking in Canada, general practitioners and specialists can do much in their practices insofar as identifying problem drinkers, using brief motivational interventions and, failing such efforts, referring patients for more specialized behavioural and pharmacologic interventions.

\section{Tony P. George}

Addiction Psychiatry Program

Department of Psychiatry

University of Toronto

Addictions Program

Centre for Addiction and Mental Health Toronto, Ont.
Competing interests: None declared.

This article has been peer reviewed.

\section{REFERENCES}

I. Adlaf EM, Begin P, Sawka E, editors. Canadian Addiction Survey (CAS). A national survey of Canadian's use of alcohol and drugs: prevalence of use and related harms. Detailed report. Ottawa: Canadian Centre on Substance Abuse; 2005. Available: www.ccsa.ca/NR/rdonlyres/6806г3оB-C314-4C9695CC-075Di4 CD8 3 DE/o/ccsaoo40282005.pdf (accessed 2007 Jan 23).

2. Bondy S, Rehm J, Ashley M, et al. Low-risk drinking guidelines: the scientific evidence. Can J Public Health 1999;90:264-70.

3. Rehm J, Giesbrecht N, Patra J, et al. Estimating chronic disease deaths and hospitalizations due to alcohol use in Canada in 2002: implications for policy and prevention strategies. Prev Chronic Dis 2006;3:AI2I.

4. Kalman D, Morissette SB, George TP. Co-morbidity of smoking in psychiatric and substance use disorders. Am J Addict 2005;I4:106-23.

5. Buonopane A, Petrakis IL. Pharmacotherapy of alcohol use disorders. Subst Use Misuse 2005;40: 200I-20.

6. Anton RF, O'Malley SS, Ciraulo DA, et al; COMBINE Study Research Group. Combined pharmacotherapies and behavioral interventions for alcohol dependence: the COMBINE study: a randomized controlled trial. JAMA 2006;295:2003-17.

7. Cohen E, Feinn R, Arias A, et al. Alcohol treatment utilization: findings from the National Epidemiological Survey on Alcohol and Related Conditions (NESARC). Drug Alcohol Depend 2007;86:214-21.
Cantiom Adterse Reaction Newsletter

\section{Bulletil cantadient des effets indésinalles}

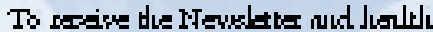
product dtsioorias fre by ermil joil

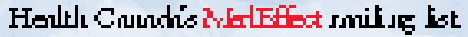

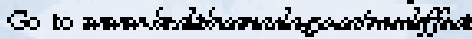

Leeriverous in h kte RelEfft: de Sutte Ciund poir reosoir Entii ersatt pirs oo וrid le B וletil et be deis nu sıyjet des prodıuits desutte Reudesols in Indrese

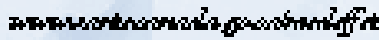

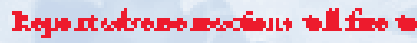

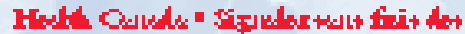

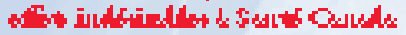

Te1rTe1 : 6662 s. 2545

Fór T<ka : 666676.6769 